\title{
HNMR-Based Metabolomics Survey in Breast Cancer Cell Line Treated by Chimera Alpha - Fetoprotein (AFP) Peptide
}

Seyedeh Masoumeh Nourolahi

Azad University Tehran North Branch

Mehdi Behdani

Pasteur Institute of Iran

Monireh Movahedi

Azad University Tehran North Branch

Delavar Shahbazzadeh ( $\square$ shahbazzadeh@yahoo.com )

Pasteur Institute of Iran

\section{Zahra Zamani}

Pasteur Institute of Iran

\section{Research Article}

Keywords: Breast cancer, alpha-feta protein, chimeric peptides, metabolomics, 1 HNMR, EBR (estrogen binging receptor).

Posted Date: July 29th, 2021

DOl: https://doi.org/10.21203/rs.3.rs-735435/v1

License: (c) (1) This work is licensed under a Creative Commons Attribution 4.0 International License. Read Full License 


\section{Abstract}

Purpose: Breast cancer is one of the most common cancer among. Chemotherapy and radiation along with surgery are common methods for treating cancer, but they exhibit side effects on normal cells in the body. We used peptides, as new anti-cancer agents, seem to have fewer reactions on the body's natural cells and are specialized markers for targeting cancer cells.

Materials and methods: Metabolomics data are obtained by ${ }^{1} \mathrm{HNMR}, \mathrm{LC} / \mathrm{MS}$ and GC/MS spectrometry and analyzed by chemometrics techniques and the affected metabolic cycles identified using different databases. ZR-75-1 cells were collected with estradiol (positive control), without estradiol (negative control) and estradiol with peptide (treatment group) and the metabolites of these 3 groups were collected by chloroform/methanol or water extraction method. Spectra were analyzed by ${ }^{1} \mathrm{HNMR}$ and chemometric methods using PLS-DA techniques by which differentiating chemical shifts and their respective metabolites were identified using the Human Metabolome Database. The differentiating metabolic pathways were detected using Metaboanalyst.ca website.

Results: A concentration of $10^{-9} \mathrm{M}$ estradiol induced the growth of estradiol-dependent ZR-75-1 cells compared to the control group. A concentration of $10^{-10} \mathrm{M} \mathrm{MH-I} \mathrm{peptide} \mathrm{inhibited} \mathrm{the} \mathrm{growth} \mathrm{of} \mathrm{estradiol-}$ induced growth in this ER + breast cancer cell line. Altered metabolites and metabolic pathway were distinguished.

Conclusion: Changes were observed in different amino acids and carbohydrates. The pathways of aminoacyl-t-RNA, glycolysis. Gluconeogenesis and biosynthesis of biotin and amino acids showed the most changes. The results from this study introduces a new peptide drug lead for the treatment of breast cancer with estrogen positive receptor.

\section{Background}

Breast cancer affects many women in 100 countries around the world and in 2018, about 2.1 million cases were diagnosed. According to statistical studies conducted in Iran, the number of cancer patients (excluding non-melanoma skin cancers) will increase from 84,800 in 2012 to 129,700 in 2025, which seems to be a significant increase as compared to other countries [1]. Lifestyle changes such as inactivity, obesity, alcohol consumption, as well as increased testosterone levels in postmenopausal women and premature menstruation can increase the risk of breast cancer. Age (especially in women over 60), personal history, breast pathology, family history, genetic history, endogenous hormones and lifestyle are other risk factors that can be mentioned. It is interesting that breastfeeding reduces breast cancer due to a decrease in endogenous sex hormones [2].

Breast cancer is classified into two categories: invasive (ductal carcinoma) and non-invasive ductal carcinoma (in situ) and lobular carcinoma [3]. Molecular classification of cancer cells is divided into 5 categories: lumina (LA) A, lumina $(L B) B, H E R+(H)$, negative triple $A(T N A)$ and negative triple $B(T N B)$ 
[4]. ZR-75-1 is a non-invasive ductal carcinoma (LA) breast cancer that affects the ducts of the breast tissue [5]. This cell line has a receptor for estrogen (ER+) and one for progesterone (PR+) with high expression of HER-2, which as a result of the presence of estradiol can stimulate the growth of this cell line [6]. There are several treatments for breast cancer, including chemotherapy and radiotherapy, as well as surgery. Chemotherapy and radiotherapy can have side effects on normal cells, they can destroy the normal cells of the person being treated [7]. Due to some special properties of peptides such as easy production, small size, high activity and specificity as well as lack of accumulation in liver and kidney tissues can be a good choice for the treatment of cancers [8].

The RGD peptide was identified by (Arg-Gly-Asp) sequence in 1997. The RGD-Tachyplesin compound can hinder the proliferation of cultured cancer cells, and it can also induce apoptosis through mitochondrial and Fas-dependent pathways [9]. MG2A peptide, with its GIGKFLHSAKKFGKAFVGEIMNSGGKKWKMRRNQ sequence, which induces necrosis and apoptosis, acts on lung and cervical cancer. Dermaseptin B2 peptide in the GLWSKIKEVGKEAAKAAAKAAGKAALGAVSEAV sequence inhibits the proliferation of breast and prostate cancer cells through necrosis. PTP7 peptide with FLGALFKALSKLL sequence affects lung, prostate and breast cancer by inducing apoptosis [10].

Omics technologies allow the display of thousands of large and small molecules using high throughput technology and chemometrics. They have the ability to measure molecules of cells such as proteins, RNAs, and intermediate metabolites in a single analysis. With these new tools, a complete assessment of the activity of different biochemical pathways and the genetic sequences between individuals and species can be made. Omics technologies comprise of different downstream techniques such as genomics, proteomics, transcriptomics and metabolomics [11]. Genomics analyzes the genetic data of a living being (the genome), transcriptomics focuses on transcription products (RNA) and proteomics is a comprehensive analysis of proteins of a studied system. Metabolomics is the study of the total profiles of metabolites in a living system [12].

Metabolites include carbohydrates, lipids, amino acids, and end products of metabolism that occur in biological samples such as cells, biological fluids, and tissues. Metabolomics is an effective way to study metabolites in a biological sample that provides useful information about the pathological and physiological conditions in a cell [8].

Techniques used to analyze metabolic data include LC/MS, GS/MS and NMR. All techniques have their own advantages, MS requires sample preparation and is destructive but more sensitive than NMR techniques which do not require sample preparation and are non-destructive. They can be used to identify a wide range of metabolites and numerous methods of chemometrics to provide information about unknown compounds [13].

In this study, the effect of chimeric EBR peptide designed by Shahbazzadeh 1995 and derived from human and rat alpha- fetoprotein, HM-I on the ZR-75-1 cells was investigated. A study of metabolomics marking the major differentiating metabolites and the important metabolic pathways in ZR-75-1 cells in the presence of the chimeric EBR peptide HM-I and estradiol was also carried out. 


\section{Methods}

\section{Peptide synthesis}

The Fmoc solid phase synthesis method was used to synthesize the peptides. Amino acids were added to a solid base (polyethylene-polystyrene) and the $\mathrm{N}$-terminus of the first amino acid was unblocked and a peptide bond attached to the $\mathrm{C}$-terminus of the second amino acid. The group of amino acids used in synthesis was protected by the fluoronyl methoxycarbonyl group (Fmoc). After the peptides were synthesized, the protecting side chain groups were removed by trifluoroacetic acid (TFA). The imported carboxylamino group was activated by the addition of the HATU (hexa fluorophosphate 0 - (- 7azabenzotriazol-1-yl) -1, 1, 3, 3, -teramethyluronium) group.

Peptides were separated from the solid base using TFA. After synthesis, 3 washes of $100 \%$ methanol were given to the resin and reaction was performed in $10 \mathrm{ml}$ of 1,2-ethanedithiol/anisole/thioanisole/TFA solution in ratios of $(3,2,5$ and 90$)$ for 1.5 grams for 5 h hours. The solid resin was then separated from the peptide solution using a glass funnel with air as a gentle stream, the filtered volume was reduced to 1 $\mathrm{ml}$ and washed off by adding $15 \mathrm{ml}$ of ethyl ether. It was then washed three times with $15 \mathrm{ml}$ of ethyl acetate/diethyl ether solution in a ratio of $(1.5,1]$ and finally, the peptides dissolved in deionized water are lyophilized. The lyophilized peptide was then dissolved in deionized water and placed on Sep-PakC18 cartridge of reverse phase chromatography or filtration gel with Sephadex G-25. The peptides are then lyophilized and dissolved in deionized water and then purified using HPLC.

All peptide amino acids are analyzed by the Water AccQ-Tag amino acid analysis system and analyzed using Mass Spectroscopy [14].

\section{Cell culture}

ZR-75-1 cells with ATCC number CRL-1500 and cell number C10099 were purchased from the National Genetic Resources of Iran. Cells are cultured in RPMI 1640 medium enriched with 10\% FBS and 1\% penicillin and incubated at $37^{\circ} \mathrm{C}, 95 \%$ humidity and $25 \% \mathrm{CO}_{2}$. Cells were isolated from the bottom of the flask by $0.25 \%$ trypsin EDTA [15].

\section{MTT for the viability test}

MTT is a type of colorimetric method using tetrazolium solution which penetrates into the cell and is converted to the aqueous crystal of fumaran by the enzyme mitochondrial succinate dehydrogenase. Inside each of the 96 microplate wells, about 180 microliters of culture medium and $5 \cdot 10^{3}$ cells were cultured and incubated for about 24 hours.

To treat the cells with estradiol, $100 \mu \mathrm{L}$ of culture medium containing $5 \cdot 10^{3}$ cells is first added to each 96-well plate and after $24 \mathrm{~h}$ incubation at $37^{\circ} \mathrm{C}$ and $5 \%$ humidity, $20 \mu \mathrm{L}$ of different concentrations $\left(4^{-10}\right.$ to $10^{-12}$ Molar) of estradiol mentioned above were added to the wells with 8 repeats. Estradiol was added at each change of the medium. On the seventh day after adding 20 $\mu$ l from MTT (tetrazolium) 
solution and incubating for 4 hours at $37^{\circ} \mathrm{C}$, the supernatant was then discarded and $100 \mu \mathrm{DMSO}$ was added and shaken for 30 min and finally, the results were analyzed by spectroscopy.

Then $20 \mu \mathrm{l}$ of different concentrations $\left(4^{-10}\right.$ to $\left.10^{-12} \mathrm{M}\right)$ of chimeric EBR peptides derived from human and rat alpha fetoprotein (HM-I \& HM-J) and EBR of human and rat with pre-determined estradiol concentration $\left(10^{-9} \mathrm{M}\right)$ was added to each of the treatment wells and all concentrations were checked by 8 replications. Cells without the addition of estradiol or peptide were called negative controls, and cells that grew in the presence of $10^{-9} \mathrm{M}$ estradiol were deemed as positive controls. MTT was carried out as described above [16].

\section{Extraction of polar and non-polar metabolites}

Flasks of $75 \mathrm{~cm}^{2}$ containing $10 \mathrm{ml}$ medium with $200 \mu \mathrm{l}$ of $1 \mathrm{nM} / \mathrm{ml}$ estradiol as positive control and the same amount of estradiol and $200 \mu \mathrm{l}$ of $10^{-8} \mathrm{M}$ concentration of $\mathrm{HM}-\mathrm{I}$ as treatment flasks were cultured for 10 days as $37^{\circ} \mathrm{C}$. After the cells reached $90 \%$ confluency they were trypsinized by $0.25 \%$ trypsin EDTA and after centrifugation for $5 \mathrm{~min}$ at $4000 \times \mathrm{g}$, the supernatant discarded and the cells were frozen with freezing solution ( $90 \% \mathrm{FBS}$ and $10 \% \mathrm{DMSO}$ ) [17], and stored in the freezer at $-80^{\circ} \mathrm{C}$. Samples were washed with $1 \times$ PBS solution and $500 \mu \mathrm{l}$ of cold chloroform/methanol solution in a ratio of 1:2 was added to all samples and vortexed. It was then shaken on an orbital shaker at $300 \mathrm{rpm}$ for 10 minutes. Then $500 \mu \mathrm{l}$ of water/chloroform with a ratio of $1 / 1$ was added to the samples and vortexed. Finally, the samples were centrifuged at $18000 \times \mathrm{g}$ for $5 \mathrm{~min}$ at $4^{\circ} \mathrm{C}$. Each sample was divided into upper phase (hydrophilic phase), middle phase (protein phase) and lower phase (lipophilic phase). The upper and lower phases were collected and sent for lyophilization [18].

\section{${ }^{1}$ HNMR spectroscopy}

The protocol applied was a standard one dimension NOESY on a Bruker ${ }^{1} \mathrm{HNMR} 500 \mathrm{~Hz}$ [19].

\section{Chemometrics data analysis}

The MATLAB platform was used using the Prometab programme on the raw NMR spectra which were then transformed into matrices to be used in multivariate analysis by the statistical analysis option of Metabo-Analyst software. The spectra were normalized and Partial Least Squares-Discriminant Analysis (PLS-DA) was carried out and the chemical shift of differentiated metabolites were obtained and identified using the Human Metabolism Database (HMDB) (www.hmdb.ca), in both the treatment and positive control groups. The name of the metabolites were entered into the Metabo-Analyst pathway analysis option (www.metaboanalyst.ca) and the main altered pathways were identified [20].

\section{Statistical analysis}

Student's $t$-test was performed on MTT values and $p$-value $<0.05$ was considered as significant.

\section{Results}


The effect of different concentrations of estradiol on stimulation of growth of ZR-75-1 cells is shown below and $1 \mathrm{nM}$ is seen to have the highest effect (Fig.1).

The cells were grown in different concentrations of chimeric peptide HM-I in the presence and absence of $1 \mathrm{nM}$ estradiol for 6 days (Fig. 2).

It is seen that the $10^{-8} \mathrm{M}$ chimeric peptide HM-I inhibited the growth of ZR-75-1 due to its anti-estradiol effect. Metabolomics studies are shown in Fig. $3 a$ and $3 \mathrm{~b}$ where the score plots of the samples are seen with a good separation between them.

The chemical shifts are identified in positive and treatment groups of hydrophilic phase $(a \& b)$, which show the most important variable points.

A comparison between the positive control and negative controls was carried out and score plots shown in Fig. 4a and 4b; and chemical shifts identified by VIP plots (Fig. 6a and 6b).

The altered metabolites in the positive control and treatment groups and are detected by the Human Metabolic Database and are shown in Table 1 and Table 2 depicts the metabolites in the positive control and negative control groups.

The differentiated metabolic pathways in the two groups of positive control and treatment groups are shown in Fig. 7a and positive and negative control groups in Fig. 7b.

\section{Discussion}

Alpha fetoprotein was reported in 1963 by Yuri S. Tatarinov as a specific antigen for human liver carcinoma (HCC). Peptide fragments of alpha fetoprotein have the potential to create a new type of anticancer agent, including the EBR peptide fragment derived from this protein, which has the ability to bind to estradiol and thus can inhibit the estradiol dependent growth of hormone-dependent cancer cells [21]. The chimeric EBR peptide derived from human and rat alpha fetoprotein (HM-I) has the ability to bind to estradiol far more than human EBR, which was determined in 1995 by Shahbazzadeh [22]. The above results indicate that the concentration of $10^{-9} \mathrm{M}$ of estradiol causes more growth of cells in the positive control than the negative control groups. By comparing this result with the results of previous studies, it can be understood that the concentration of $10^{-9} \mathrm{M}$ of estradiol which is equivalent to $1 \mathrm{nM}$ has the ability to stimulate the growth of estradiol recipient cells compared to cells in the negative group [14].

The results showed that the concentration of $10^{-8} \mathrm{M}$ of the chimeric peptide HM-I with binding to estradiol reduces the growth of cells in the treatment group compared to the cells in the control group. However, comparing the negative control group with the treated one, which is the only effect of the peptide in the absence of estradiol, showed that HM-I singly has no anti-cancer effect on the ZR-75-1 cancer line. In 2008, Sierralta and colleagues worked on an alpha-fetoprotein (Cp) derivative of the 9esophageal ring. This peptide inhibits the growth of MCF7 and ZR-75-1 cell lines by binding to estradiol 
while showed no inhibitory effect on estrogen receptor-free breast cancer, MDA-MB231 [23]. But so far no research has been done on the chimeric EBR fragment created of HM-I. The rat EBR binds to estradiol with a higher affinity than human one, and this chimerization promotes the binding of HM-I to estradiol [22]. It should also be noted that in this study, altered metabolic pathways in breast cancer cell of ZR-75-1 class in the presence of estradiol as well as in the presence of estradiol and chimeric peptide were investigated and thus showed the mechanism of action of estradiol in inducing cell growth and also the inhibition of cell growth in the simultaneous presence of estradiol and peptide.

Altered metabolites of ZR-75-1 cells in a culture containing estradiol include glucose, 17a-estradiol, 16alpha-hydroxyestrone, biotin, leucine, tryptophan, arginine, NADPH, pantothenic acid, glutamic acid and lipids (Table 1). Glucose is one of the modified metabolites, and tumor cells use the anaerobic glycolysis pathway (ATP) to produce energy (ATP) faster, which is known as the Warberg effect which produces energy faster than glucose and creates an acidic environment (lactic acid) to protect cancer cells [24]. And because it produces less ATP per glucose molecule, it increases the uptake of glucose by increasing the expression of glucose transporters, including $\mathrm{Na}+$-dependent glucose transporters (SGLTS) and facilitating glucose transporters (GLUTs) in this cell line [25]. Giuseppe Tripod and colleagues used vitamins, including biotin, as carriers of anti-cancer drugs, arguing that cancer cells needed more vitamins such as biotin to divide and multiply rapidly and biotin can increase the growth of cancer cells, thus being able to act as a suitable vector for anti-cancer drug [26]. Estradiol is one of the compounds that were added to the culture medium of cancer cells at the time of culture and enters the cell through estrogen receptors. The compounds estradiol, estrone and estriol are the main types of estrogen. These compounds of estrogen and the estrogen receptor and estrogen-related metabolites such as 16 alpha-OH can be associated with cancer risk [27].

NADPH is another modified metabolite in this project. It is an essential source of electrons for the synthesis of steroids, amino acids and fatty acids that enhance the rapid growth of tumor cells. It provides the electrons needed for iron-sulfur protein (Fe/S) fusion, which participates in the synthesis of unnecessary amino acids and the formation of lipoic acid, modifications in the tRNA molecule, replication of the DNA molecule and its repair, as well as telomere protection. The enzyme dihydrofolate reductase (DHFR) catalyzes the reduction reaction of conversion of dihydrofolate to tetrahydrofolate (THF) in folate metabolism using NADPH which is required for the biosynthesis of some amino acids, methionine, thymidylate and purines [28]. As the lipids are involved in rapid and uncontrolled proliferation of cancer cells, loss of molecular adhesion and the ability to communicate with other cells, failure to repair DNA damage and ultimately, the ability to tolerate apoptosis by active lipid metabolism in cancer cells [29].

Other altered metabolites are leucine and tryptophan amino acids, in which tryptophan stops the cell cycle in the $\mathrm{G} 1$ phase and the proliferation of T lymphocytes. By activating the non-depressible kinase GCN2 pathway, it produces a modulated stress response that ultimately provides the energy responsible for T cells and formation apoptosis. kynorene (Kyn) and downstream metabolites of tryptophan can activate the aryl hydrocarbon receptor (AHR). These metabolites also involved in Treg detection and T lymphocytes and natural killer cells (NK) inhibited by them [30]. Leucine is an essential, branched-chain 
amino acid that acts as a signaling molecule in the mTOR signaling pathway. Leucine is the most important amino acid involved in protein synthesis, however, if cancer cells do not have access to this amino acid, it does not have a significant effect on these cells [31]. Pantothenic acid and glutamic acid are other metabolites that have undergone changes in these cancer cells that can play an important role in the growth and proliferation of these cells.

Progressive lipid metabolism and mitochondria, mitochondrial leucine metabolism and citric acid cycle can be mentioned as important reactions that the presence of pantothenic acid (vitamin B5) as a precursor of coenzyme A (COA). Pantothenic acid acts as a coagulant and acyl- carrier protein and has a protective role against oxygen species [30]. Changes in the path of glutamine metabolism can be seen in many cancers. Mitochondrial glutaminase catalyzes the conversion of glutamine to glutamate and increases the amount of this enzyme in cancers. Glutamine provides the nitrogen needed to synthesize nucleotides and hexamine, and some unnecessary amino acids are synthesized in the presence of glutamine as the nitrogen donor [32].

In our study, altered metabolic pathways in the presence of estradiol as well as the concomitant presence of estradiol and chimeric peptide include: the aminoacyl-tRNA biosynthesis pathways, glycolysis and gluconeogenesis, galactose metabolism, biotin metabolism, arginine biosynthesis, alanine aspartate and glutamate metabolism, glutathione metabolism, arginine-proline metabolism, and tryptophan metabolism. They are consistent with previous studies of Yang et al., 2020, working on altered metabolic pathways in breast cancer cells in another study by using ${ }^{1}$ HNMR metabolomics showing the metabolic pathways of amino acids and aminoacyl-tRNA [33]. Aru Singh and colleagues in 2017 worked on the metabolic pathways of breast cancer that showing the alanine aspartate and glutamate metabolism, glycolysis and gluconeogenesis pathways are altered which is consistent with our study [34].

In cancer cells, there is a link between increased cell growth rate and proliferation, metabolism and protein synthesis. T-RNA expression is higher in cancer cells than in normal cells, this increase in expression is often associated with high expression of TFIII factor compounds. Microarray performed in 2009 by Pavon-Eternod et al. was able to measure the levels of tRNA molecules in 3 categories of normal breast epithelial cell groups and 6 categories of breast cancer cells and reported high expression of all types of tRNA in breast cancer cells. Arginine biosynthesis is another altered metabolic pathway [34]. The glycolysis and gluconeogenesis pathways are other altered in breast cancers are consistent with the results of our research and increase glycolysis and decrease gluconeogenesis to produce more energy are indicators of cancer cells [34]. UDP-galactose, the active form of galactose, is a galactosyl donor for the biosynthesis of glycoproteins and glycolipids, indicating that galactose metabolism is required for many cancer cell functions, such as cell-cell detection, metastasis, and receptor-modulated signaling. In fact, it can be said that carbohydrate metabolism affects the growth of cancer cells [36].

L-Arginine is an essential amino acid for cancer cell growth and is obtained by biosynthesis or by adsorption from culture medium in vitro. Arginine enters the cell through cationic amino acid transporters (CATs), and the enzymes arginine synthase and nitric oxide synthase use this amino acid to produce 
ornithine and nitric oxide (NO) compounds. Both of these compounds are needed for cell proliferation, including cancer cells [37]. The glutathione metabolism pathway is seen in our study, and the antioxidant glutathione can act on the drug metabolites, thus protecting cancer cells from drug poisoning [38].

The metabolic pathways was observed in the treated and positive control groups and negative control along with the positive control group that are quite similar to each other. This is due to the fact that the peptide blocks estrogen but does not affect cancer cells at all, hence its response is due to the presence and absence of estrogen and not the peptide.

\section{Conclusion}

Chimeric peptide $\mathrm{HM}-\mathrm{I}$ at a concentration of $10^{-8} \mathrm{M}$ by blocking estradiol and preventing its binding to the estradiol receptor, prevents estradiol-dependent growth of breast cancer cell ZR-75-1 (ER+). Estradiol affects the biosynthesis pathway of aminoacyl tRNA, metabolic pathways of amino acids including arginine biosynthesis, tryptophan metabolism and arginine-proline metabolism, glycolysis and gluconeogenesis pathways, biotin metabolism, cellular metabolism of galactose metabolites. Now, with the presence of chimeric peptide HM-I in the presence of estradiol and blockade of this hormone by this peptide, the metabolic pathways mentioned above have undergone a change leading to a decrease, which indicates the effective function of this peptide in inhibiting estradiol.

\section{Declarations}

\section{Acknowledgements}

Not applicable.

\section{Authors' contributions}

SD designed the study and revised the article. NSM collected and accessed relevant literature. ZZ and BM organized the content and structure of the literature. NSM, ZZ and SD corrected the content of the article and drew illustrations. All authors have read and approved the manuscript.

\section{Funding}

Not applicable.

\section{Availability of data and materials}

If anyone request the data from this study, please contact Zahra Zamani (zamani@pasteur.ac.ir).

\section{Declarations}

Ethics approval and consent to participate. This study was reviewed and approved by the review board and ethics committee of Research council of Pasteur Institute of Iran. All methods were performed in 
accordance with the Declaration of Helsinki. No administrative permissions were required to access and use the data/records described in this study.

\section{Consent for publication}

Not applicable.

\section{Competing interests}

The authors declare that they have no competing interests, and all authors should confirm its accuracy.

\section{Author details}

1Biochemistry Dept., Faculty of Life Sciences, Azad University Tehran North Branch, Tehran, Iran. 2Venom and Biotherapeutics Molecules Lab., Medical Biotechnology Department, Biotechnology Research Centre, Pasteur Institute of Iran, Tenran, Iran.

3Biochemistry Dept., Pasteur Institute of Iran, Tehran, Iran.

\section{References}

1. ABACHIZADEH K, KERAMATINIA A. Anticipating cancer rates of Iran in 2025. 2016.

2. Shah R, Rosso K, Nathanson SD. Pathogenesis, prevention, diagnosis and treatment of breast cancer. World journal of clinical oncology. 2014;5(3):283.

3. Sharma GN, Dave R, Sanadya J, Sharma P, Sharma K. Various types and management of breast cancer: an overview. Journal of advanced pharmaceutical technology \& research. 2010;1(2):109.

4. Dai X, Cheng H, Bai Z, Li J. Breast cancer cell line classification and its relevance with breast tumor subtyping. Journal of Cancer. 2017;8(16):3131.

5. Kadivar A, Ibrahim Noordin M, Aditya A, Kamalidehghan B, Davoudi ET, Sedghi R, et al. Antiproliferative effects of imatinib mesylate on ZR-75-1 and MDA-MB-231 cell lines via PDGFR$\beta$, PDGF-BB, C-Kit and SCF expression Corrigendum in/10.3892/ijmm. 2019.4119. International journal of molecular medicine. 2018;42(1):414 - 24.

6. Subik K, Lee J-F, Baxter L, Strzepek T, Costello D, Crowley P, et al. The expression patterns of ER, PR, HER2, CK5/6, EGFR, Ki-67 and AR by immunohistochemical analysis in breast cancer cell lines. Breast cancer: basic and clinical research. 2010;4:117822341000400004.

7. Majeed W, Aslam B, Javed I, Khaliq T, Muhammad F, Ali A, et al. Breast cancer: major risk factors and recent developments in treatment. Asian Pac J Cancer Prev. 2014;15(8):3353-8.

8. Escudero N, Marhuenda-Egea F, Lopez-Llorca LV. Metabolomics. Perspectives in Sustainable Nematode Management Through Pochonia chlamydosporia Applications for Root and Rhizosphere Health: Springer; 2017. p. 169-81. 
9. Hu C, Chen X, Zhao W, Chen Y, Huang Y. Design and modification of anticancer peptides. Drug Des. 2016;5(3):1000138.

10. Gaspar D, Veiga AS, Castanho MA. From antimicrobial to anticancer peptides. A review. Frontiers in microbiology. 2013;4:294.

11. Debnath M, Prasad GB, Bisen PS. Molecular diagnostics: promises and possibilities: Springer Science \& Business Media; 2010.

12. Horgan RP, Kenny LC. 'Omic'technologies: genomics, transcriptomics, proteomics and metabolomics. The Obstetrician \& Gynaecologist. 2011;13(3):189-95.

13. Wang $H$, Wang $L$, Zhang $H$, Deng $P$, Chen J, Zhou B, et al. ' ${ }^{H}$ NMR-based metabolic profiling of human rectal cancer tissue. Molecular cancer. 2013;12(1):121.

14. Joseph LC, Bennett JA, Kirschner KN, Shields GC, Hughes J, Lostritto N, et al. Antiestrogenic and anticancer activities of peptides derived from the active site of alpha-fetoprotein. Journal of peptide science: an official publication of the European Peptide Society. 2009;15(4):319-25.

15. Parker KA. Storage of cell lines. Cancer Cell Culture: Springer; 2011. p. 27-34.

16. Jose J, Sudhakaran S, Kumar S, Jayaraman S, Variyar EJ. A comparative evaluation of anticancer activities of flavonoids isolated from Mimosa pudica, Aloe vera and Phyllanthus niruri against human breast carcinoma cell line (MCF-7) using MTT assay. International Journal of Pharmacy and Pharmaceutical Sciences. 2014;6(2):319-22.

17. Jiang W, Zhou L, Lin S, Li Y, Xiao S, Liu J, et al. Metabolic profiles of gastric cancer cell lines with different degrees of differentiation. International Journal of Clinical and Experimental Pathology. 2018;11(2):869.

18. Li Y, Wang C, Li D, Deng P, Shao X, Hu J, et al. 1H-NMR-based metabolic profiling of a colorectal cancer CT-26 lung metastasis model in mice. Oncology Reports. 2017;38(5):3044-54.

19. Vicente-Muñoz S, Morcillo I, Puchades-Carrasco L, Payá V, Pellicer A, Pineda-Lucena A. Nuclear magnetic resonance metabolomic profiling of urine provides a noninvasive alternative to the identification of biomarkers associated with endometriosis. Fertility and sterility. 2015;104(5):12029.

20. Zhou J, Wang Y, Zhang X. Metabonomics studies on serum and urine of patients with breast cancer using 1 H-NMR spectroscopy. Oncotarget. 2017;5.

21. Terentiev A, Moldogazieva N. Alpha-fetoprotein: a renaissance. Tumor Biology. 2013;34(4):2075-91.

22. Shahbazzadeh D. Estrogen binding activities of recombinant alpha-fetoproteins expressed in yeast. [Hokkaido igaku zasshi] The Hokkaido journal of medical science. 1995;70(3):473-83.

23. Sierralta WD, Epuñan MJ, Reyes JM, Valladares LE, Andersen TT, Bennett JA, et al. A peptide derived from alpha-fetoprotein inhibits the proliferation induced by estradiol in mammary tumor cells in culture. Oncology reports. 2008;19(1):229-35.

24. Li N, Tan W, Li J, Li P, Lee S, Wang Y, et al. Glucose metabolism in breast cancer and its implication in cancer therapy. 2011. 
25. Barbosa AM, Martel F. Targeting glucose transporters for breast cancer therapy: the effect of natural and synthetic compounds. Cancers. 2020;12(1):154.

26. Tripodo G, Mandracchia D, Collina S, Rui M, Rossi D. New perspectives in cancer therapy: the biotinantitumor molecule conjugates. Med Chem. 2014;8:1-4.

27. Khatami F, Payab M, Sarvari M, Gilany K, Larijani B, Arjmand B, et al. Oncometabolites as biomarkers in thyroid cancer: a systematic review. Cancer Management and Research. 2019;11:1829.

28. Ju H-Q, Lin J-F, Tian T, Xie D, Xu R-H. NADPH homeostasis in cancer: functions, mechanisms and therapeutic implications. Signal Transduction and Targeted Therapy. 2020;5(1):1-12.

29. Huang C, Li Y, Tu Y, Freter CE. Breast Cancer and Lipid Metabolism. Lipidomics in Health \& Disease: Springer; 2018. p. 113-35.

30. Onesti CE, Boemer F, Josse C, Leduc S, Bours V, Jerusalem G. Tryptophan catabolism increases in breast cancer patients compared to healthy controls without affecting the cancer outcome or response to chemotherapy. Journal of translational medicine. 2019;17(1):239.

31. Kang J-S. Dietary restriction of amino acids for Cancer therapy. Nutrition \& metabolism. 2020;17(1):1-12.

32. Goode G, Gunda V, Chaika NV, Purohit V, Yu F, Singh PK. MUC1 facilitates metabolomic reprogramming in triple-negative breast cancer. PloS one. 2017 May 2;12(5):e0176820.

33. Yang L, Wang Y, Cai H, Wang S, Shen Y, Ke C. Application of metabolomics in the diagnosis of breast cancer: a systematic review. Journal of Cancer. 2020;11(9):2540.

34. Singh A, Sharma RK, Chagtoo M, Agarwal G, George N, Sinha N, et al. 1H NMR metabolomics reveals association of high expression of inositol 1, 4, 5 trisphosphate receptor and metabolites in breast cancer patients. PLoS One. 2017;12(1):e0169330.

35. Mleczko AM, Celichowski P, Bąkowska-Żywicka K. Ex-translational function of tRNAs and their fragments in cancer. Acta Biochimica Polonica. 2014;61(2).

36. Tang M, Etokidem E, Lai K. The Leloir pathway of galactose metabolism-a novel therapeutic target for hepatocellular carcinoma. Anticancer research. 2016;36(12):6265-71.

37. Too CK, Abdelmagid SA. L-arginine uptake and its role in the survival of breast cancer cells. LArginine in Clinical Nutrition: Springer; 2017. p. 253-68.

38. Chen C, Gao J, Wang T-S, Guo C, Yan Y-J, Mao C-Y, et al. NMR-based metabolomic techniques identify the toxicity of emodin in HepG2 cells. Scientific reports. 2018;8(1):1-10.

\section{Tables}

Table 1: The main metabolic pathways in the hydrophilic and lipophilic phases of the positive control group and treatment 


\section{Positive control and treatment group}

\begin{tabular}{|c|c|c|c|c|c|c|}
\hline Number & Variation & $\begin{array}{l}\text { Chemical } \\
\text { shifts }\end{array}$ & Level & Location & Metabolites & $\begin{array}{l}\text { HMDB } \\
\text { Number }\end{array}$ \\
\hline 1 & $\begin{array}{l}\text { V957 } \\
\text { V958 }\end{array}$ & $\begin{array}{l}3.7175 \\
3.7125\end{array}$ & $\downarrow$ & $\begin{array}{l}\text { lip- } \\
\text { ext\&hyd- } \\
\text { ext }\end{array}$ & L-Leucine & $\begin{array}{c}\mathrm{HMDB} 0000 \\
687\end{array}$ \\
\hline 2 & $\begin{array}{l}\text { V956 } \\
\text { V955 }\end{array}$ & $\begin{array}{l}3.7225 \\
3.7275\end{array}$ & $\downarrow$ & hyd-ext & $\begin{array}{l}\text { Glucose 1- } \\
\text { phosphate }\end{array}$ & $\begin{array}{c}\text { HMDB0001 } \\
586\end{array}$ \\
\hline 3 & V960 & 3.7025 & $\downarrow$ & hyd-ext & alpha-D-Glucose & $\begin{array}{c}\mathrm{HMDB} 0003 \\
345\end{array}$ \\
\hline 4 & $\begin{array}{l}\text { V1132 } \\
\text { V1131 } \\
\text { V1138 }\end{array}$ & $\begin{array}{l}2.7825 \\
2.7875 \\
2.7525\end{array}$ & $\downarrow$ & $\begin{array}{l}\text { lip- } \\
\text { ext\&hyd- } \\
\text { ext }\end{array}$ & Biotin & $\begin{array}{c}\mathrm{HMDB} 0000 \\
030\end{array}$ \\
\hline 5 & V1130 & 2.7925 & & hyd-ext & $\mathrm{NADPH}$ & $\begin{array}{c}\text { HMDB0000 } \\
221\end{array}$ \\
\hline 6 & V1135 & 2.7775 & & hyd-ext & $\begin{array}{l}\text { 2'-Deoxyguanosine } \\
\text { 5'-monophosphate }\end{array}$ & $\begin{array}{c}\text { HMDB } 0001 \\
044\end{array}$ \\
\hline 7 & V991 & 3.4875 & $\downarrow$ & hyd-ext & Pantothenic acid & $\begin{array}{c}\text { HMDB0000 } \\
210\end{array}$ \\
\hline 8 & & $\begin{array}{l}1.5325 \\
1.5375\end{array}$ & $\downarrow$ & lip-ext & $\begin{array}{c}\mathrm{TG}(18: 1(9 \mathrm{Z}) / 18: 1(9 \\
\mathrm{Z}) / 18: 1(9 \mathrm{Z}))\end{array}$ & $\begin{array}{c}\mathrm{HMDB} 0005 \\
453\end{array}$ \\
\hline 9 & & 1.2575 & $\downarrow$ & lip-ext & $\mathrm{CE}(16: 0)$ & $\begin{array}{c}\mathrm{HMDB} 0000 \\
885\end{array}$ \\
\hline 10 & & 7.2625 & $\downarrow$ & lip-ext & L-Tryptophan & $\begin{array}{c}\mathrm{HMDB} 0000 \\
929\end{array}$ \\
\hline 11 & & 1.6825 & $\uparrow$ & lip-ext & L-Arginine & $\begin{array}{c}\mathrm{HMDB} 0000 \\
517\end{array}$ \\
\hline
\end{tabular}

Table 2: Altered metabolites in the hydrophilic and lipophilic phases of the positive control group and the treatment. 
(Positive and Negative control groups)

\begin{tabular}{|c|c|c|c|c|c|}
\hline Number & $\begin{array}{c}\text { Chemical } \\
\text { shifts }\end{array}$ & Level & Location & Metabolite & HMDB Number \\
\hline 1 & 3.7275 & & hyd-ext & Glucose 6-phosphate & HMDB0001401 \\
\hline 2 & 2.7925 & 1 & hyd-ext & L-Glutamic acid & HMDB0000148 \\
\hline 4 & 2.7625 & & hyd-ext & 16a-Hydroxyestrone & HMDB0000335 \\
\hline 5 & 2.8025 & $\downarrow$ & hyd-ext & alpha-D-Glucose & HMDB0003345 \\
\hline 6 & 2.7875 & $\downarrow$ & hyd-ext & 17a-Estradiol & HMDB0000429 \\
\hline 7 & $\begin{array}{l}7.2575 \\
7.2525\end{array}$ & $\uparrow$ & lip-ext & L-Tryptophan & HMDB0000929 \\
\hline 8 & $\begin{array}{l}1.2575 \\
1.2575\end{array}$ & $\uparrow$ & lip-ext & $\mathrm{CE}(16-0)$ & HMDB0000885 \\
\hline 9 & $\begin{array}{l}3.7325 \\
3.7375\end{array}$ & $\downarrow$ & lip-ext & L-Lysine & HMDB0000182 \\
\hline 10 & $\begin{array}{l}3.7175 \\
3.7125\end{array}$ & $\downarrow$ & lip-ext & Glucose 1-phosphate & HMDB0001586 \\
\hline 11 & $\begin{array}{l}2.7625 \\
2.7675\end{array}$ & $\downarrow$ & lip-ext & 16b-Hydroxyestrone & HMDB0000347 \\
\hline 12 & 1.7525 & $\downarrow$ & lip-ext & $\mathrm{TG}(18: 1(9 \mathrm{Z}) / 18: 1(9 \mathrm{Z}) / 18: 1(9 \mathrm{Z}))$ & HMDB0005453 \\
\hline
\end{tabular}

Figures 


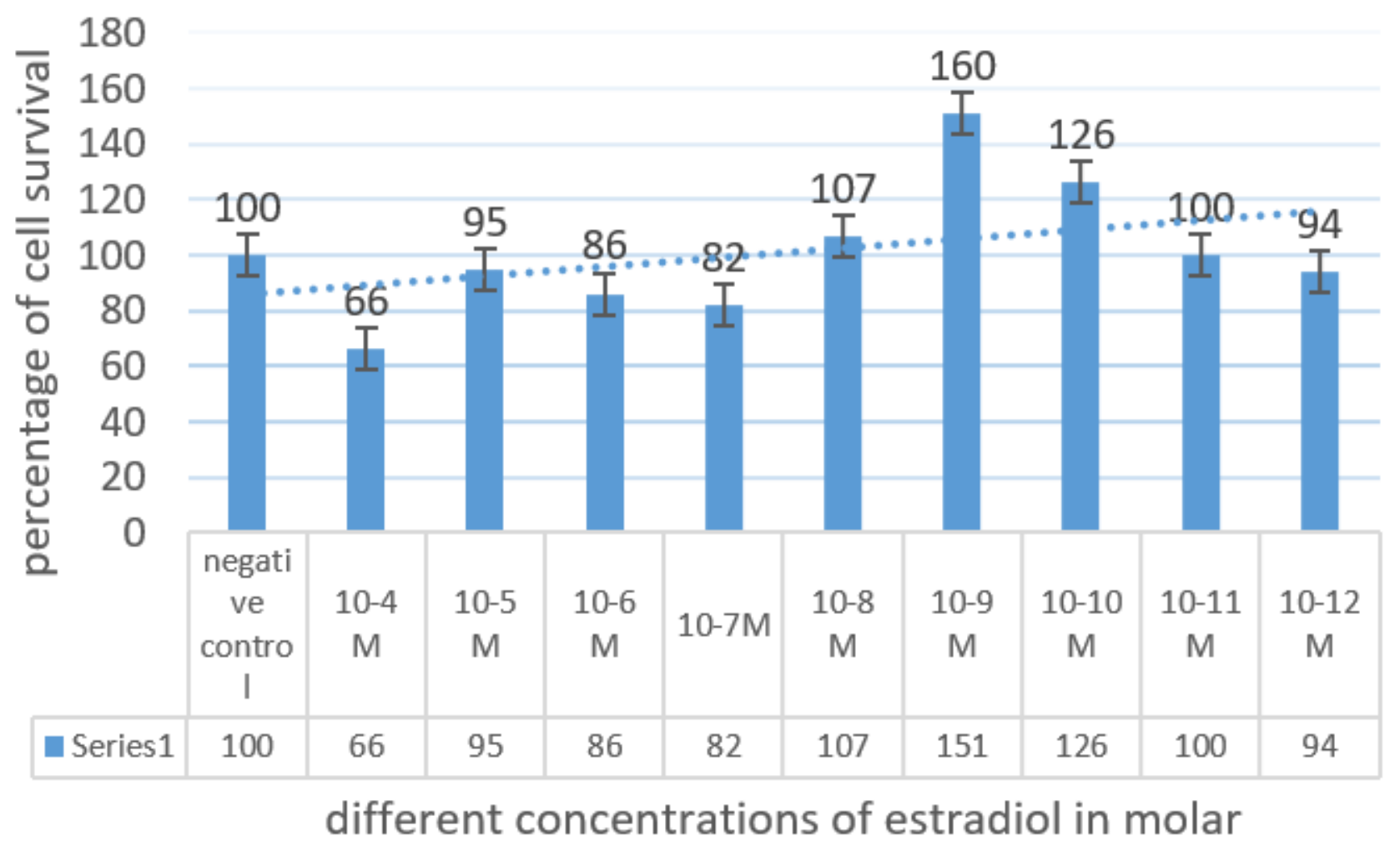

Figure 1

The effect of different concentrations of estradiol on ZR-75-1 cell proliferation. 


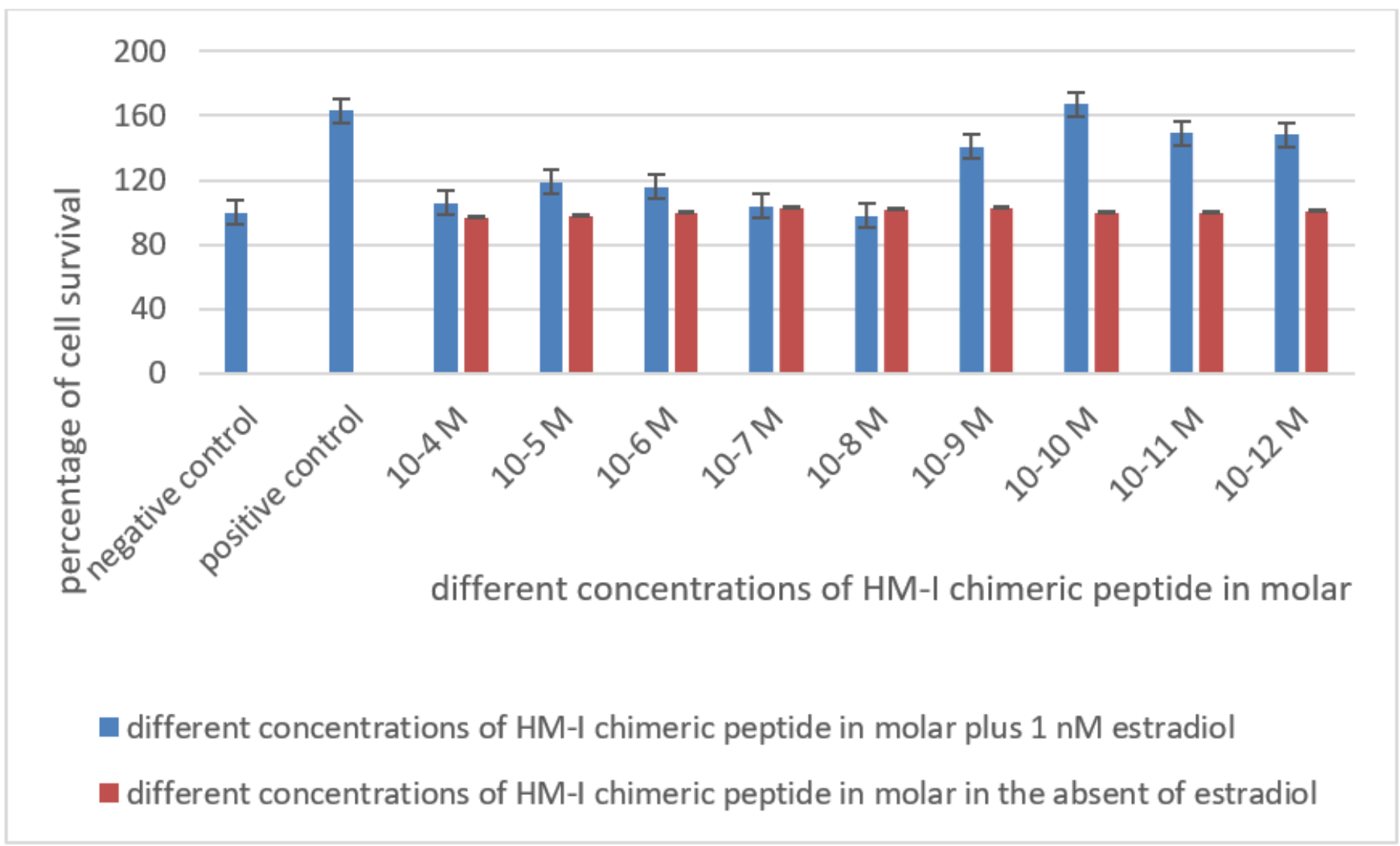

Figure 2

The effect of different concentrations of chimeric peptide HM-I on cell proliferation. 


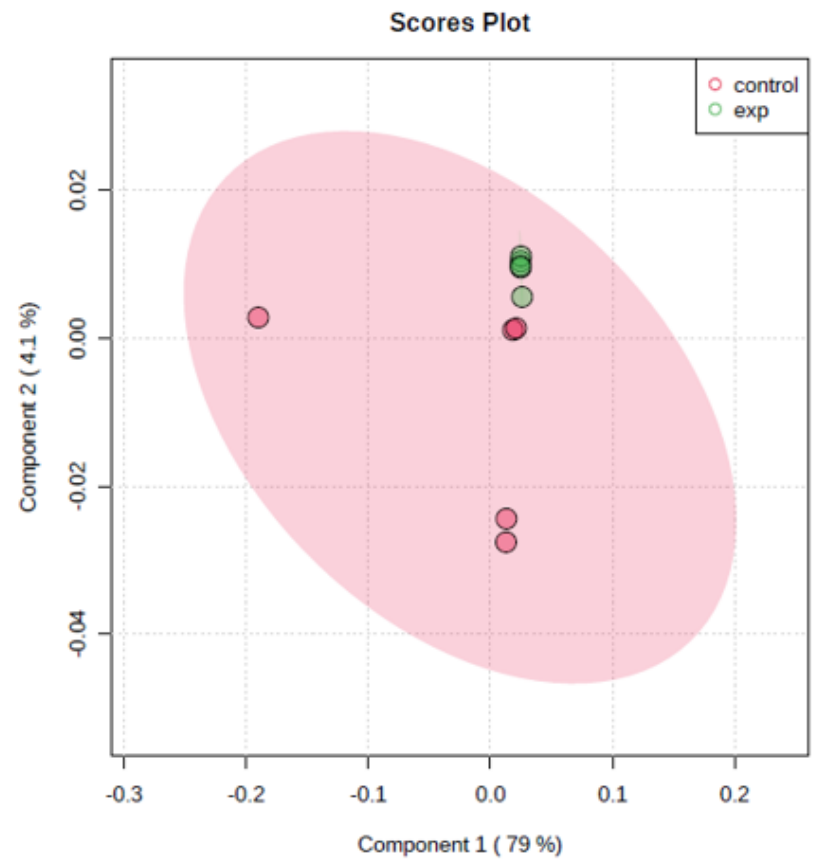

a

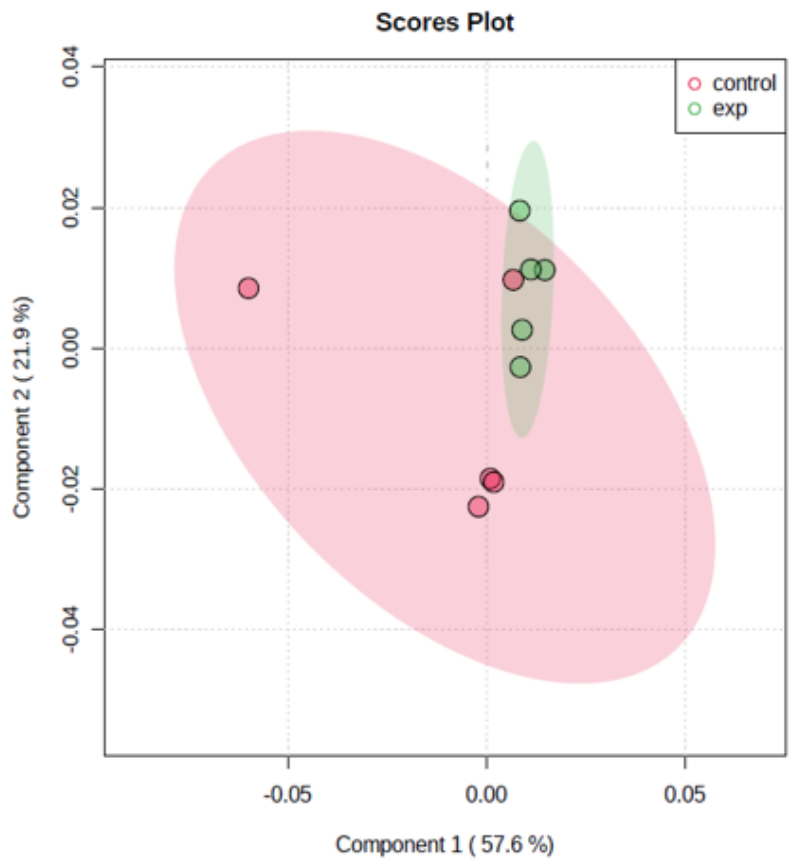

b

\section{Figure 3}

PLS-DA of hydrophilic phase of positive control and treatment groups (a). PLS-DA of lyophilic phase of positive control and treatment after PLS-DA (b).

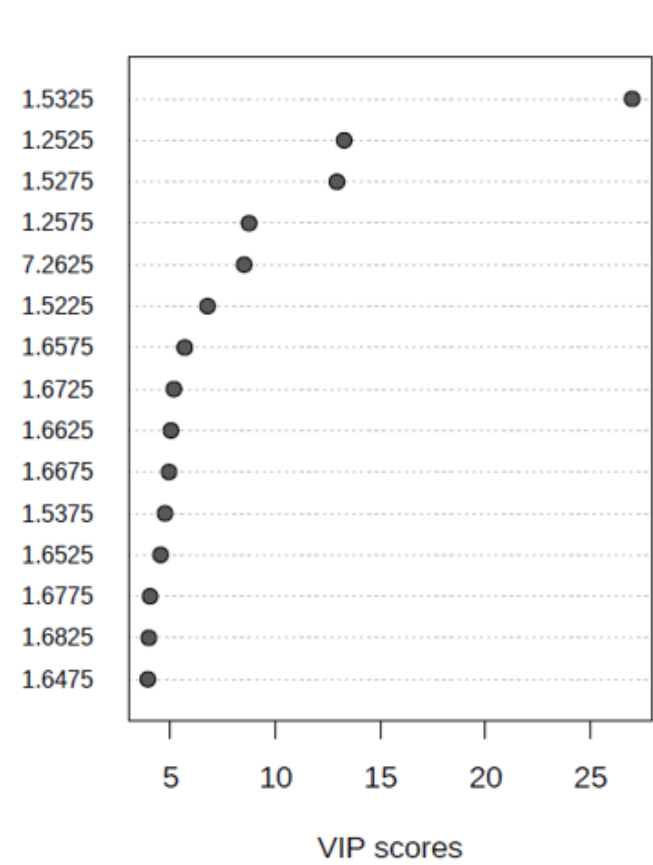

a

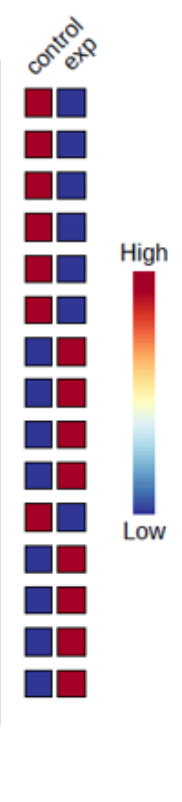


Figure 4

Identification of chemical shifts from variable numbers in positive and treatment groups of hydrophilic phase (a). Identification of chemical shifts from variable numbers in positive and treatment groups of lypophilic phase (b).

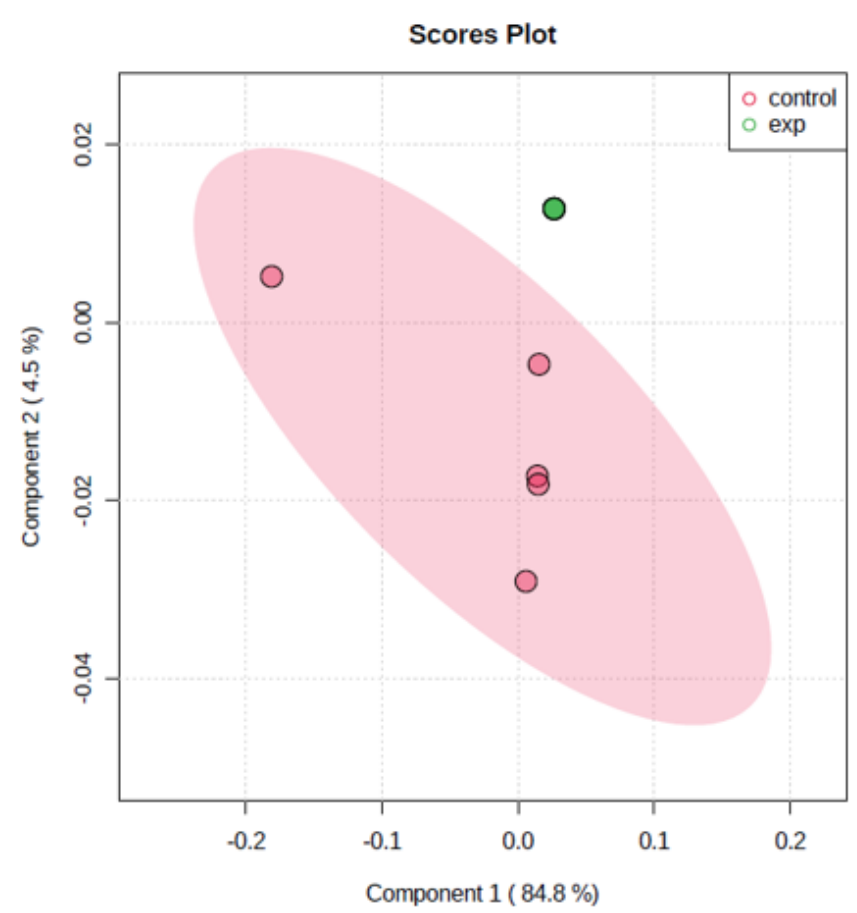

a

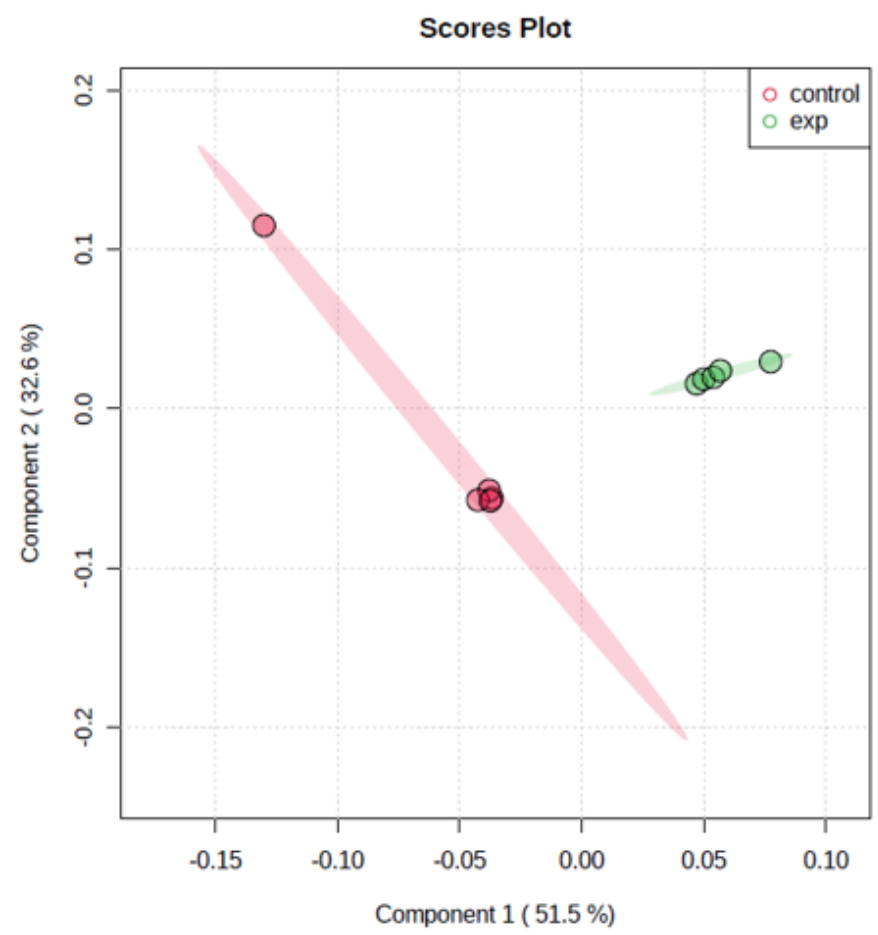

b

Figure 5

PLS-DA of hydrophilic phase of positive control and negative controls (a). PLS-DA lyophilic phase of positive control and negative controls after PLS-DA (b). 


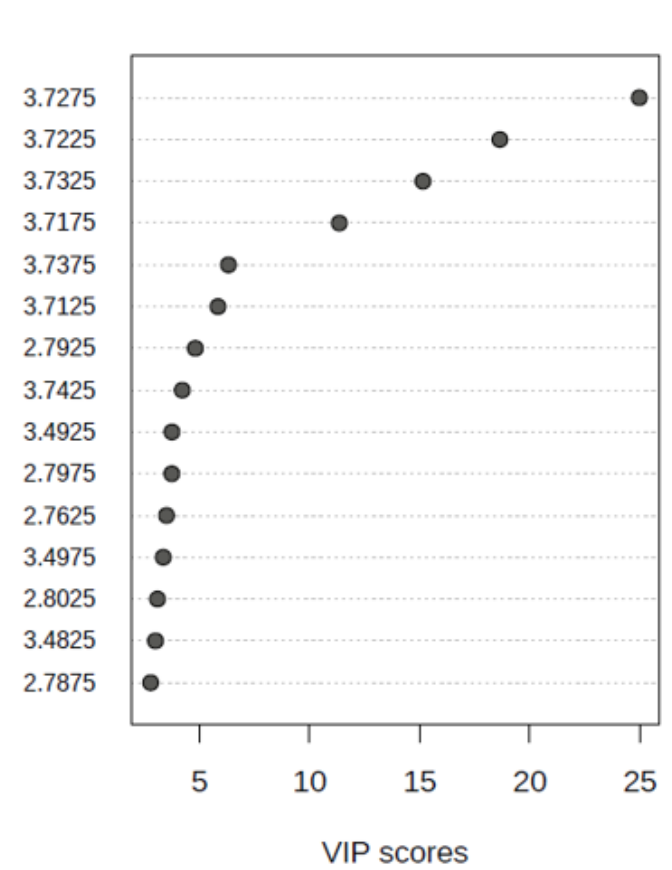

a

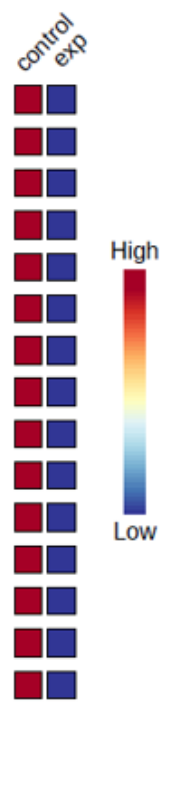

7.2575
7.2625
3.7275
7.2525
3.7225
1.2525
1.2575
3.7325
1.5325
3.7175
2.7625
2.7675
3.7375
1.5275
3.7125
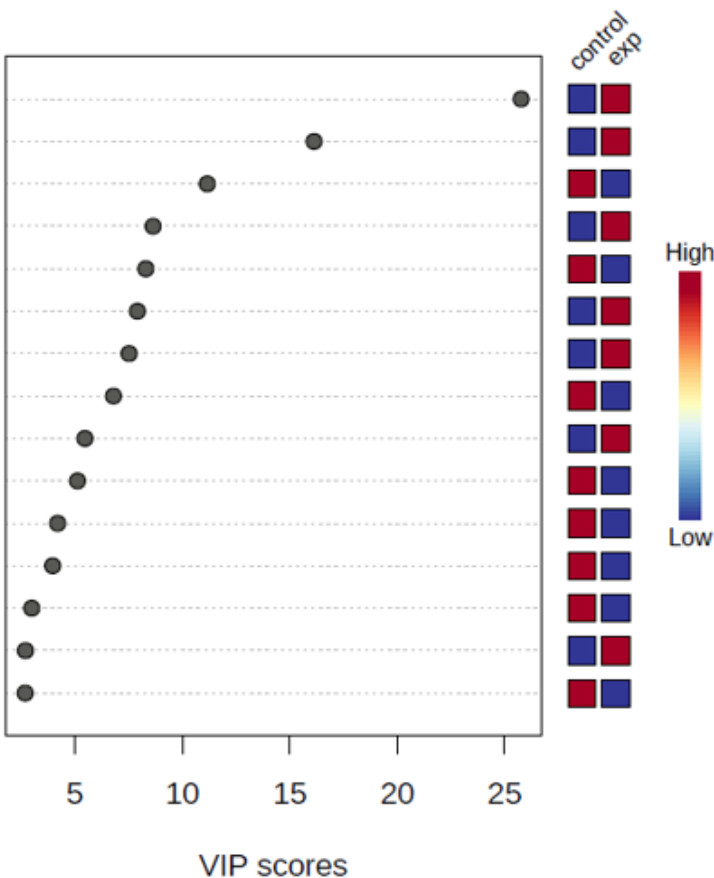

$\mathrm{b}$

\section{Figure 6}

Identification of chemical shifts from variable numbers in positive control and negative controls of hydrophilic phase (a). Identification of chemical shifts from variable numbers in positive control and negative controls of lypophilic phase (b).
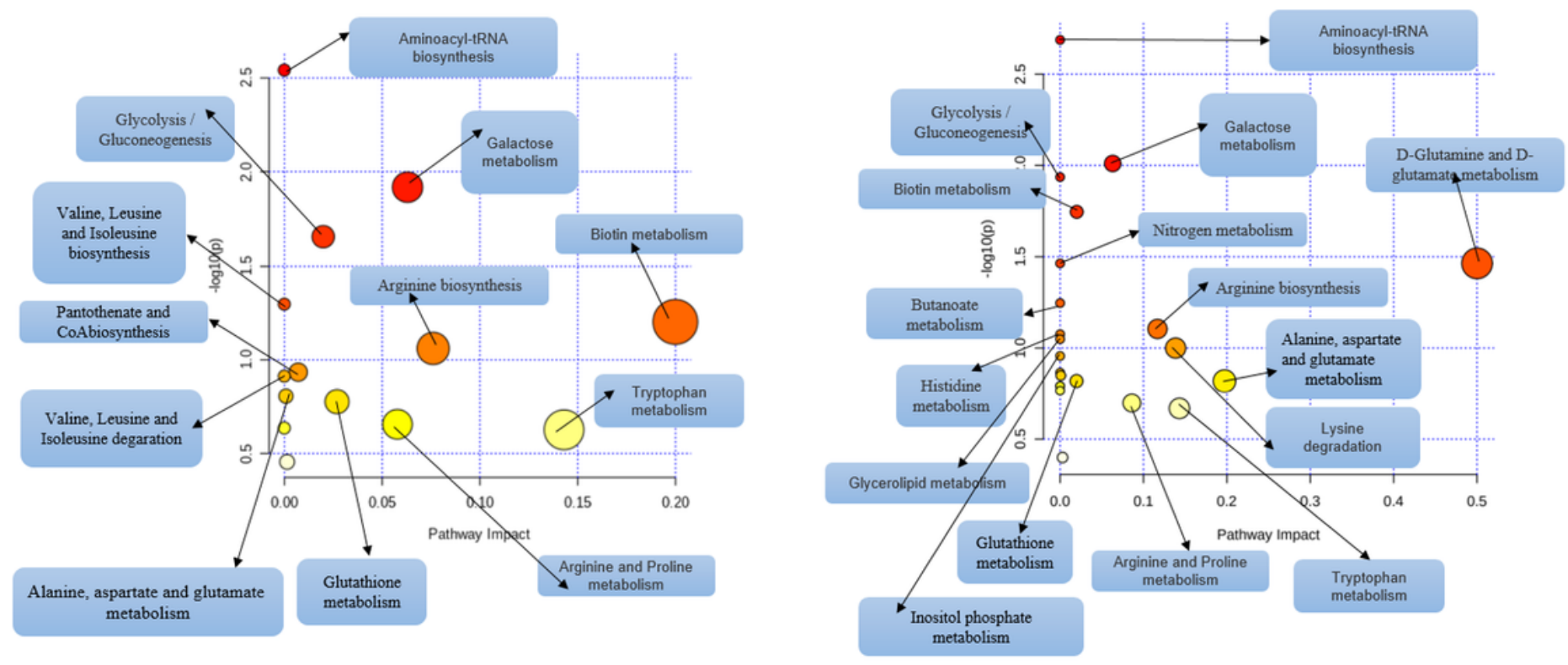

A

B

Figure 7 
a. The main metabolic pathways in the hydrophilic and lipophilic phases of the positive control group and treatment. $b$. The major metabolic differentiating pathways in the hydrophilic and lipophilic phases of the positive and negative control groups. 